\title{
BASIC DESIGN OF THE PARS PETROCHEMICAL PORT BREAKWATERS WITHIN A REGION OF DEEP WATER AND HIGH SEISMIC ACTIVITY
}

\author{
Babak Banijamali ${ }^{1}$ and Morteza Banijamali ${ }^{2}$,
}

\begin{abstract}
This article addresses certain notable breakwater design aspects for the rare case of the Pars Petrochemical Port, where fairly slender rubble-mound breakwaters are located in water depths exceeding 32 meters within a seismically active zone. Due to the cryogenic cargo pipe-racks being placed atop breakwater crests, the design process has had to be concerned with seismic risks where the stability and deformations of breakwaters during earthquakes are important enough to govern the overall design as well as the more conventional hydraulic and geotechnical considerations. Moreover, some construction related issues pertinent to this fast-track project and the use of dredged material in the breakwater core are also discussed.
\end{abstract}

Keywords: rubble-mound breakwater; seismic design; limit-equilibrium methods; finite-elements; apparent cohesion

\section{INTRODUCTION}

The recently constructed Pars Petrochemical Port is situated in the Assalueh region of the Iranian province of Bushehr, as shown in Fig. 1. The port will serve the export of petrochemical products derived from the vast Pars offshore gas field which contains the largest world reserves of its kind. The port owner is the National Petrochemical Company (NPC) of Iran as the second largest exporter of petrochemicals in the Middle-East region. $\mathrm{DBC}$ has been responsible for all basic designs and international tender documents preparations as well as subsequent tender evaluations, detailed designs review and construction supervision tasks.

In order to construct the port facilities, interesting planning, design, engineering challenges and geological conditions had to be overcome. These challenges rarely, if ever, have all had to be recognized, investigated, resolved, planned, designed and constructed for simultaneously in a single project, including the following:

- Due to the landlocked topography of the coastal region, particularly the presence of the nearby Zagros mountain range, only a narrow strip of usable land remained for development. The main (western) and lee (eastern) breakwaters had to be constructed seaward of the petrochemical plants, construction of which had previously been accomplished on reclaimed land. As a result, the breakwaters were located for the most parts in water depths much greater than those previously attempted to construct such structures in the Middle-East. As depicted in the bathymetry chart, Fig. 2, after an initial start in the water depth of 12 (m), due to the rather steep seabed slope, the main breakwater continues for most of its length in water depths of up to $33(\mathrm{~m})$ with respect to the Chart Datum of the project, defined at the Lowest Astronomical Tide level of the site.

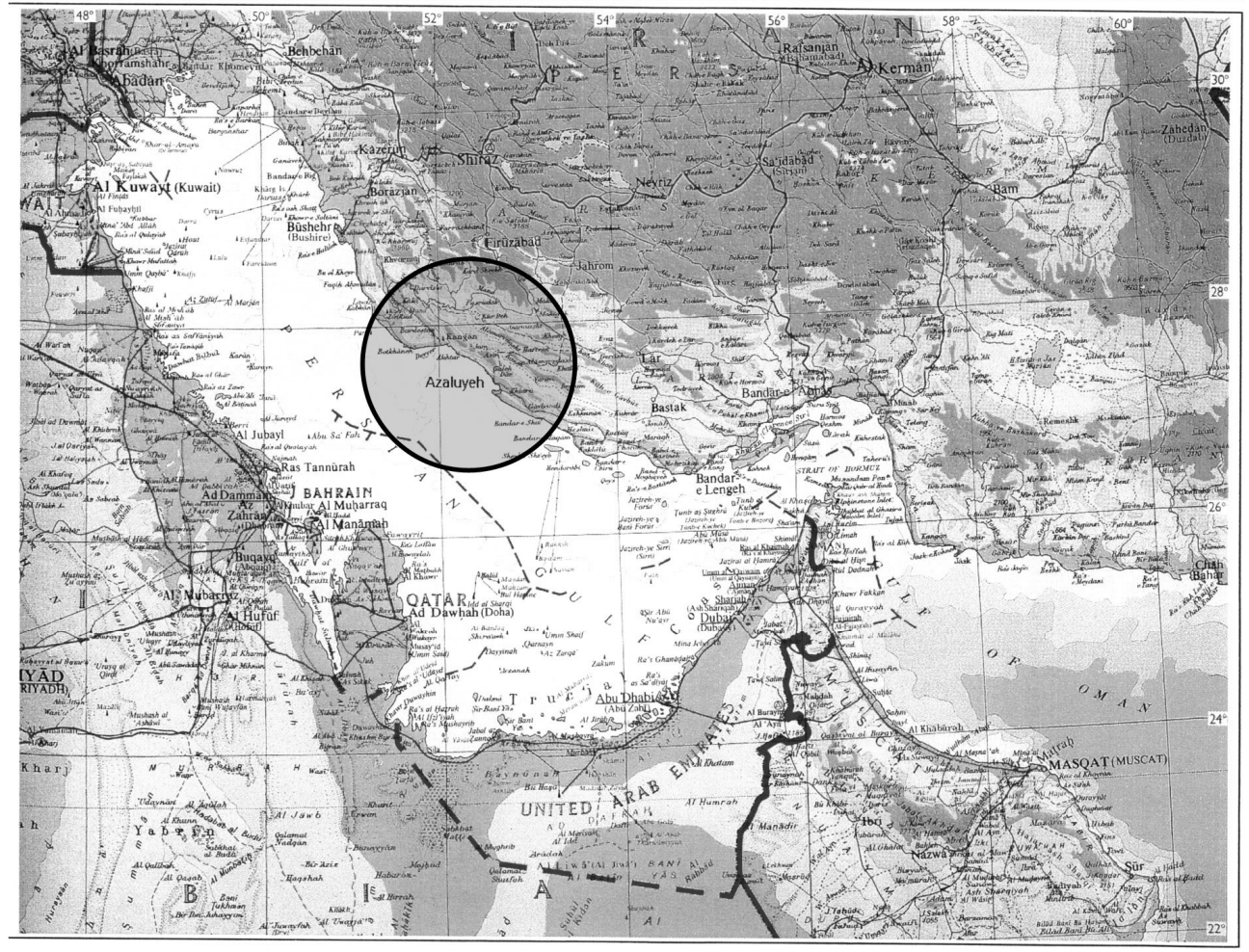

Figure 1. Location of the Pars Petrochemical Port at the Assalueh Region, a.k.a. Azaluyeh.

\footnotetext{
${ }^{1}$ Ph.D., Coastal Engineering Division Director, Darya-Bandar Consulting Engineers (DBC), No. 9, South Kaj Lane, Zabety Ave., Heravi Sq., Tehran, Post Code: 1667739113, Iran. Email: Babak.Banijamali@dbc.ir

${ }^{2}$ M.Sc., Chairman \& Managing Director, Darya-Bandar Consulting Engineers (DBC), No. 9, South Kaj Lane, Zabety Ave., Heravi Sq., Tehran, Post Code: 1667739113, Iran. E-mail: Morteza.Banijamali@dbc.ir
} 
- Another characteristic feature of the project was the significant seismic activity in the area around the site. Although, breakwaters are often designed to withstand mainly waves and hydraulic related phenomena, in this project the location of pipelines on top of breakwater crests carrying liquid cryogenic cargo to the adjacent berths required that both the stability and deformation of the breakwaters after a major possible earthquake had to be analyzed because of the site being located very close to active fault-lines. In other words, the breakwaters for this project were not only mere wave attenuation structures but also they had to serve as industrial structures, where it was striven within budgetary constraints to minimize any required future maintenance and repair costs due to effects of both wave action as well as earthquakes.

Furthermore, to facilitate the export of liquid cargo, 6 berths were designed adjacent to the main breakwater in water depths ranging from 14 to $30(\mathrm{~m})$, as well as 2 berths adjacent to the lee breakwater.

\section{BREAKWATER DESIGN}

Based on pertinent investigations and analyses, including: wave climate, soil survey, sediment transport, currents measurements \& modeling (Fugro 2002), as well as a quantitative risk analysis (DNV 2002), the layouts of the breakwaters were finalized as in Fig. 2. Notably, the breakwater lay-outs were selected to ensure harbour tranquility considering the dominant north-westerly sector of wave attack.

Although, a wide range of alternative breakwater designs were investigated during the conceptional design stages, however, eventually a statically stable rubble-mound type of breakwater was selected. The choice of the rubble-mound alternative was influenced by criteria including the abundant existence of rock quarries -albeit, not always yielding rock of desirable quality- in the vicinity of the project site, significant local experiences of Iranian contractors with this type of structure over the past four decades, longevity of rock in the highly corrosive environment of the Persian Gulf, less wave reflections inside the fairly narrow harbour basin from the inclined porous faces of the rubble-mound, and relatively less construction costs as well as duration of construction issues.

\section{HYDRAULIC DESIGN ASPECTS OF THE RUBBLE-MOUND STRUCTURE}

Based on the Extremal analysis of all data including hindcast results, available in-situ measurements, ship observations and altimetry wind and wave data, a design significant wave-height of $5.2(\mathrm{~m})$ was determined. As the present paper does not focus on the hydraulic design aspects therefore further such detail is not provided.

The typical breakwater cross-section drawings are provided as in Fig.s 3 to 5. Moreover, Table 1 summarizes the stone mass values, as follows:

\begin{tabular}{|c|c|}
\hline \multicolumn{2}{|c|}{ Table 1. Final Stone Weight Specifications for Various Layers } \\
\hline Layer Name: & $\begin{array}{c}\text { Antifer/Stone mass } \\
(\mathrm{Kg})\end{array}$ \\
\hline Armour for most trunk sections (IV-a) & 14,000 \\
\hline Armour for curves \& head sections (IV-c) & 18,000 \\
\hline Upper filter (III) & $1,000-3,000$ \\
\hline Upper berm (III-a) & $2,000-4,000$ \\
\hline Lower filter (II) & $200-1,000$ \\
\hline Lower berm (II-b) & $100-500$ \\
\hline Core (I) & Up to 200 \\
\hline
\end{tabular}

It deserves mention that the layer II-a, as shown in the drawings, was not really different from the core layer (I) but in this way the drawings point to a stricter requirement to enforce the design gradation during construction phase for the main wave action zones. This was necessary to avoid washing away of the fines which had escaped segregation at quarries and also to mitigate the effects of at times achieving in practice smaller median weights for the core layer by the contractor compared to what was specified in the contract.

Using Hudson \& related formulae, the concrete armour blocks were designed after taking into consideration theoretical \& practical implications of using various types of slender, bulky and massive concrete armour blocks. Computations of wave run-up and overtopping were also performed to optimize the crest height considering the location of the piperack on breakwater crest.

Owing to past international case-histories as well as DBC's own design experiences in Iran which have shown that some slender armour units such as Tetrapods may become subject to breakage either during or after placement, therefore it was opted to use Antifer blocks (Layer IV-a: each Antifer unit weighing 14.0 tons along the two straight segments of the trunk and layer IV-c: composed of 18.0 tons units along the bends and head sections) to avoid this problem in line with the recent international recurrence of interest in using simple massive units.

Moreover, evolved bulky type units such as Accropode or Core-Loc units with high stability coefficient values were not considered due to a lack of a sufficient degree of local construction experience to justify their use, particularly in water depths exceeding 30 (m), as well as international licensing issues. Moreover, it was 
feared that in case of rather poor construction the theoretical stability associated with these advanced units may not be achieved. Such a risk under the design wave was deemed unwarranted due to its drastic consequences requiring major repair operations and/or causing repair-related down-time and its resulting costs after the port has become operational.

Initially, based on existing quarry reports from nearby rock quarries and design code recommendations, upper and lower filter layer gradation specifications (for the upper filter and upper berm layers III and III-a: rock in the range of 1 to 3 tons and for the lower filter and berm layers: stones from 100 kilograms to 1 ton were specified) were determined and seen to fulfill the relevant gradation criteria for adjacent layers and provide adequate filtering without any problems being observed during physical model tests (WL | Delft Hydraulics 2002). However, during detailed design, to further mitigate risks it was accepted by client to change the III-a layer range to consist of 2 to 4 tons. Furthermore, layer II-b was defined by the 100 to 500 kilograms gradation at the final design stages to reduce the gradation range by the client in comparison to the case of using layer II instead of II-b. The core layer gradation was set with the constraints of minimizing quarry waste, costs and any wave transmission to inside the harbour (Layer I: the stone range of 1 to 100 kilograms was initially chosen to fulfill all technical criteria, however the gradation upper-limit was extended to 200 kilograms solely because of quarries yield and construction preferences during the detailed design stage).

To validate the design, 2D \& 3D (WL | Delft Hydraulics 2002) physical hydraulic model tests were utilized and armour layer \& toe stability as well as wave run-up and over-topping were investigated for both perpendicular and oblique wave attack at the breakwater trunk and head sections. Even though, the physical modelling endeavors with the initial design all demonstrated sufficient structural stability, due to Client's preferences based on contractor's suggestions to still lower the risks, the upper range of the upper berm layer IIIa was increased from 3 to 4 tons.

Regarding stone characteristics, using past local experiences of constructing rubble-mound breakwaters in warmer climates particularly that of the Persian Gulf - where freezing action is not present - technical specifications of the stone materials were finalized in line with requirements suggested by most design codes, however, allowing a relatively larger water absorption percentage which was shown to be viable from past local experiences existing in the region from decades ago.

As stringent time requirements of the construction project implied that the substantial target daily stone placement rate of up to $15,000\left(\mathrm{~m}^{3}\right)$ was to be achieved and sustained for almost two years, a combination of land-based \& sea-borne operations was decided upon. Therefore, all construction below the $-5(\mathrm{~m})$ level was to be performed by suitable bottom/side-dumping barges as well as other sea-borne equipment such as floating cranes; and the remainder of the breakwater cross-section was constructed by land-based equipment.

During the course of construction, desirable daily stone placement rates of $10,000\left(\mathrm{~m}^{3}\right)$ were quite often achieved and at times exceeded owing to a combination of factors such as suitable advance planning and the concerted land and sea-based efforts being aided by fairly calm seas.

As a means of performing value engineering, upon obtaining acceptable results for the physical and chemical properties of the dredged spoils, made available from the Boskalis dredging campaign (these parameters were used to represent the dredged material in the pertinent stability and deformation analyses of the breakwaters), it was decided to replace up to a maximum of approximately $7(\mathrm{~m})$ of the lowest part of the core layer stone by dredged material to be situated as close as possible to the axis of the core layer and confined as much as possible by two small underwater dikes at both ends of the core layer (constructed a priori by using the bottom-dump split barge) to stop the loss of fine material and their spreading into the adjacent sea-side and leeside berm layers. However, such spreading was not a problem as both field current measurements and modelling results did not show a great potential for the movement of the spoils at depths exceeding $30(\mathrm{~m})$. Of course, to realistically and holistically implement a cost saving associated with the quarrying and transport operations of the core layer material and also to reduce the required construction time, important issues of reviewing quarry fragmentation curves - to ensure that there would indeed be an overall saving achievable and core material would not have to be produced anyway as a by-product just to yield enough filter type of rock sizes- were considered. Fortunately, as up to 15 separate quarries were used to supply the sufficient rock quantity for this project, with some being better suited to yield filter than core gradation rock sizes and vice-versa, therefore the proposed selective replacement of core material by dredged material, despite the associated discontinuity in the rock weights used during construction, did actually cause a considerable increase in the execution speed as well as resulting in cost savings not only in breakwater construction but also dredging operations, reducing also the maximum discharge distance for the dredging which otherwise would had to be released in water depths exceeding $40(\mathrm{~m})$ in line with the prevailing environmental constraints.

Notable from a practical perspective is the fact that as the core layer started to progress faster using dredged spoils, it became crucial to speed up the execution of the underlayers and the armour layer to safeguard the economical and execution time related gains against the risk of seasonal storm waves damaging the unprotected cross-section during the construction period. 


\section{SEISMIC AND GEOTECHNICAL DESIGN ASPECTS}

Often, it is common practice to finalize the design of rubble-mound breakwaters taking into consideration solely hydraulic and geotechnical issues not having to take the issue of earthquake stability and related deformations of the rubble-mound into consideration, owing in part to the relatively high magnitudes of the related horizontal accelerations associated with water wave impact on these structures, which amount around the gravitational acceleration (CIRIA 2007).

Although, it has already been documented (OCDI 2001) that seismic considerations particularly for the design of slender, deep-water breakwaters in regions with fairly mild waves and significant seismic activity constitute a clear case requiring special investigation and analysis, however, not many such design examples can apparently be readily found around the world. However, as the Pars Petrochemical Port breakwaters are located in a region of significant seismic activity (p.g.a. for L1 and L2 earthquake levels are: $0.23 \mathrm{~g}$ and $0.42 \mathrm{~g}$, respectively), along with the fact that the export pipe-rack with stringent requirements on its maximum allowable vertical and horizontal displacements passes on top of breakwater crests, therefore it became even more important to investigate the breakwater stability and deformations during and after the occurrence of the design earthquake.

\section{Slope-Stability of the Rubble-Mound Breakwater}

Prior to delving into the description of the performed analysis and its results, it is necessary to discuss the length of return period as an issue related to adopting a coherent design philosophy. Because the return period for the design wave has been taken to be 100 years based on structure life-time and permitted level of risk, it may be reasonably argued from a statistical point of view that the same return period should be the coherent choice for the design earthquake. However, as the consequences of earthquakes can be much more drastic for the breakwater structure with the pipe-rack on its crest, as well as less reliable data being available for more infrequent earthquakes than waves, therefore, the client required that the L2 earthquake event with a return period of 475 years be taken as the design earthquake. Even though from a hydraulic point of view the breakwater was designed in a fairly conventional manner of taking a return period of 100 years for the design wave and using the traditional 5\% damage hydraulic stability coefficient values associated with the armour units the earthquake associated risk was treated more conservatively. In fact, the requirement to check the L2 level earthquake for the breakwater as a Class (S) special industrial structure, as also advocated by OCDI 2001, does interestingly form somewhat of a contradiction at least from a statistical point of view when comparing to the usual practice of taking a return period of 100 years for the design wave.

However, by decoupling to some extent the pipe-rack from the breakwater via the means of a pile-driven substructure, it is possible to define the breakwater as a Class (A) ordinary structure and only have to check its stability for the considerable L2 earthquake level while the deformations are still to be checked for the more improbable L1 event according to OCDI 2001 recommendations.

Notably, a sensitivity analysis shows that the choice of the rock mechanical parameters, namely the internal angle of friction $(\varphi)$ and the apparent cohesion $\left(c^{\prime}\right)$ parameter values for the rubble material greatly influences the outcome of analysis for both slope stability and deformations. In the absence of tri-axial test results for large rock specimens under their actual loading conditions after construction, the design values recommended by existing design codes (OCDI 2001) (CIRIA 2007) are the only source of guidelines for parameter selection. Specifically, a $\varphi$ of 35 degrees -provided the compressive strength exceeded $30\left(\mathrm{MN} / \mathrm{m}^{2}\right)$ and if not a reduced value of 30 degrees- and a c' of 10 to $20\left(\mathrm{kN} / \mathrm{m}^{2}\right)$, irrespective of the compressive strength, due to lateral confinement and interlocking in the rubble-mound is advocated in the above-mentioned revered design references.

Even though, the stone specifications in the construction contract implied the possibility of taking the abovementioned parameter values at the high end, however, owing to the great sensitivity of the calculations to parameter values, importance of the project, possible deviations from rock quality specifications during execution, as well as client's preferences to further reduce risks, a somewhat more conservative selection basis for the parameter values than suggested in the above-mentioned references was adopted to finalize the design.

During construction, a stone quality committee was set up with representatives from client, consultant and contractor and it was procedurized to ensure, by performing the relevant ASTM tests, that at least the following criteria are met during the construction: Actual dry specific gravity to exceed 2.25, water absorption below $7 \%$, soundness test limit of $10 \%$, compressive strength above $300\left(\mathrm{~kg} / \mathrm{cm}^{2}\right)$, impact resistance threshold of $25 \%$, and abrasion resistance (a.k.a. Los Angeles) test result for 500 revolutions to be less than $35 \%$.

It deserves mention that our search points to the scarcity of existing scientific material and therefore a clear need to perform additional theoretical and field work, perhaps on an international scale, to obtain what can be a more realistic representation of rock mechanical properties for rubble-mound breakwater structures than the present state of documented knowledge, based on limited results obtained from back-calculations related to previously damaged rubble structures in Japan (OCDI 2001), where in order to make the theoretical results more in line with the reality it was suggested to include a measure of apparent cohesion in the Mohr-Coulomb behavioral model when considering the property of rock in rubble-mounds. 
Clearly, it is the lee-side of the breakwaters which is most vulnerable to slope instability represented by shallow slip circles rather than the sea-side face which is also better protected against waves. Therefore, solely an account of the sensitivity analysis performed for a range of parameter values pertaining to the lee side using the Slope/W limit equilibrium module of Geoslope software is provided as follows in this article.

To account for the uncertainties, a Monte-Carlo analysis related to the factor of safety for approximately 30,000 slip-circles was undertaken, varying in this process the $\varphi$ values from 35 to 40 degrees, c' from 10 to 20 $\left(\mathrm{kN} / \mathrm{m}^{2}\right)$ and the seismic coefficient being set ranging from a third to a half of the p.g.a. value, obtaining the results as summarized in table 2 below:

\begin{tabular}{|c|c|c|}
\hline \multicolumn{3}{|c|}{ Table 2. Slope Stability Results for the Lee-Side Face } \\
\hline Lee-side slopes: & $\begin{array}{c}\text { Probability of Failure by: } \\
\text { Simplified Bishop method }\end{array}$ & $\begin{array}{c}\text { Probability of Failure by: } \\
\text { Morgenstern-Price method }\end{array}$ \\
\hline $1: 1.5$ & $8 \%$ & $6 \%$ \\
\hline $1: 1.7$ & $5 \%$ & $3 \%$ \\
\hline $1: 2.0$ & $0.5 \%$ & $0.2 \%$ \\
\hline
\end{tabular}

As from a mathematical point of view, the Morgenstern-Price method, based on the balance of both interslice forces and moments, is the most accurate of all existing limit-equilibrium relationships including the wellused Simplified Bishop method, therefore, results based on the former are favoured here. Eventually, although the initially suggested side-slopes of 1:1.5 were acceptable from a seismic failure probability point of view (specially for the sea-side face), however, to reduce risks further the client decided on the 1:1.7 slope for both breakwater sides, even though this would be relatively more conservative for the seaside face, as the initially proposed 1:1.5 slope already corresponded to less than 5\% probability of failure.

\section{Rubble-Mound Deformations and Pipe-Rack Sub-Structure}

The objective here was to investigate the expected total combined vertical settlement due to rubble-mound itself and the soil underneath it, for the case of L2 earthquake event, considering the rubble-mound interaction with the piled pipe-rack substructure, and to compare this settlement value to the maximum allowable threshold set from cryogenic cargo piping considerations.

The finite-element analysis of the rubble-mound breakwater under the design earthquake was performed utilizing the Plaxis software using the above-mentioned parameter values. Evidently, for the breakwater alone a maximum vertical displacement in the order of $30(\mathrm{~cm})$ was likely for the crest (with rubble-mound parameters set as in [OCDI 2001]). In greater depths, additional means were necessary to reduce vertical settlement during earthquakes.

Based on the client's preference, a piled-foundation substructure for the pipe-rack was designed by driving steel piles in the core of breakwaters and further additionally to $10(\mathrm{~m})$ in the sea-bed to limit maximum allowable vertical settlements to less than $7(\mathrm{~cm})$. It has to be however mentioned that the associated horizontal displacements during earthquakes for this system were still quite large.

As for the characteristics of the driven steel piles inside the breakwater core, these mostly consisted of piles with 42 inch diameters, wall thickness of $26(\mathrm{~mm})$ and X70 steel grade. As the project execution coincided with the height of international price appreciation for steel prior to the global recession, piles were chosen also on the basis of going for the cheapest available with a minimum lead time. Cathodic Protection was also foreseen in the critical splash zone for all berthing and the rack substructure.

\section{BERTHS ADJACENT TO BREAKWATERS}

Various types of gravity \& piled structures were initially considered and compared from technical, construction and economical points of view to be selected for the 6 berths located adjacent to the main breakwater.

A typical drawing is provided as in Fig. 8 for the eventually selected steel pipe piles and prefabricated concrete deck berthing structure, even though a concrete block-type gravity structure could also fulfill the required structural criteria. It deserves mention that instead of the dolphin pile configuration, large diameter monopiles were preferred for some of the berths, as depicted in Fig. 8.

\section{CONCLUSIONS}

Breakwaters of the Pars Petrochemical Port, are the deepest such structures in the Persian Gulf and the region, having posed interesting concurrent challenges related to hydraulic, geotechnical and seismic aspects. From a construction point of view, using solely the capabilities of local marine contractors in Iran to construct such grand breakwaters and performing value engineering during construction were some of the other challenges faced on a new regional scale in this project.

In particular, this article reported the useful know-how generated regarding the design of fairly slender breakwaters located in earthquake-prone deep-water regions, pointing also to the need for further international 
research in formulating rock mechanical properties to facilitate less idealized analysis of rubble-mound breakwaters under similar conditions.

\section{ACKNOWLEDGEMENTS}

The preparation and of this article has been funded by DBC research and knowledge dissemination programme.

\section{REFERENCES}

ARGOSS. 2002. Online wind and wave data-base of the world.

CIRIA; CUR AND CETMEF. 2007. The Rock Manual. The use of rock in hydraulic engineering (2nd edition). C683, CIRIA, LONDON, 1268 pp.

Det Norske Veritas (DNV). 2002. Report no. 2002-0338: Quantitative Risk Analysis of the Pars Petrochemical Port.

Fugro. 2002. Geophysical and Current Measurement Surveys of the Pars Petrochemical Port.

Fugro. 2002. Report no. IR/811/01/02: Marine Geotechnical Investigations of the Pars Petrochemical Port.

International Institute of Earthquake Engineering and Seismology (IIEES). 2002. Seismology Study of the Assalueh region.

The Overseas Coastal Area Development Institute of Japan (OCDI). 2001. Technical Standards \& Commentaries for Port and Harbour Facilities in Japan.

Water Research Centre of the Iranian Ministry of Power. 2003. Physical Modelling of the breakwaters of the Pars Petrochemical Port.

WL | Delft Hydraulics. 2002. 2D and 3D physical Model Tests of the Pars Petrochemical Port breakwaters. 


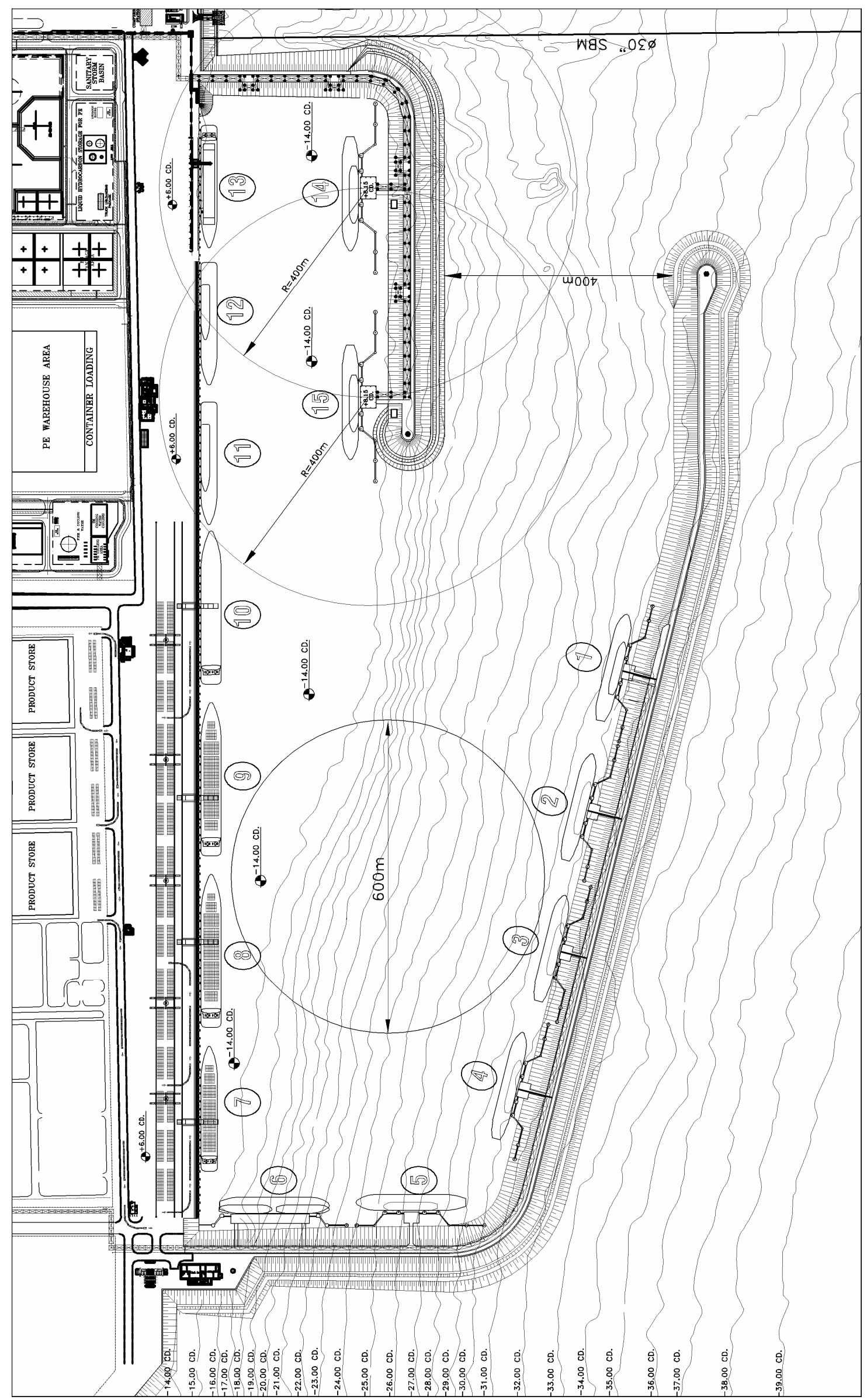

Figure 2. Lay-out of Breakwaters of the Pars Petrochemical Port 


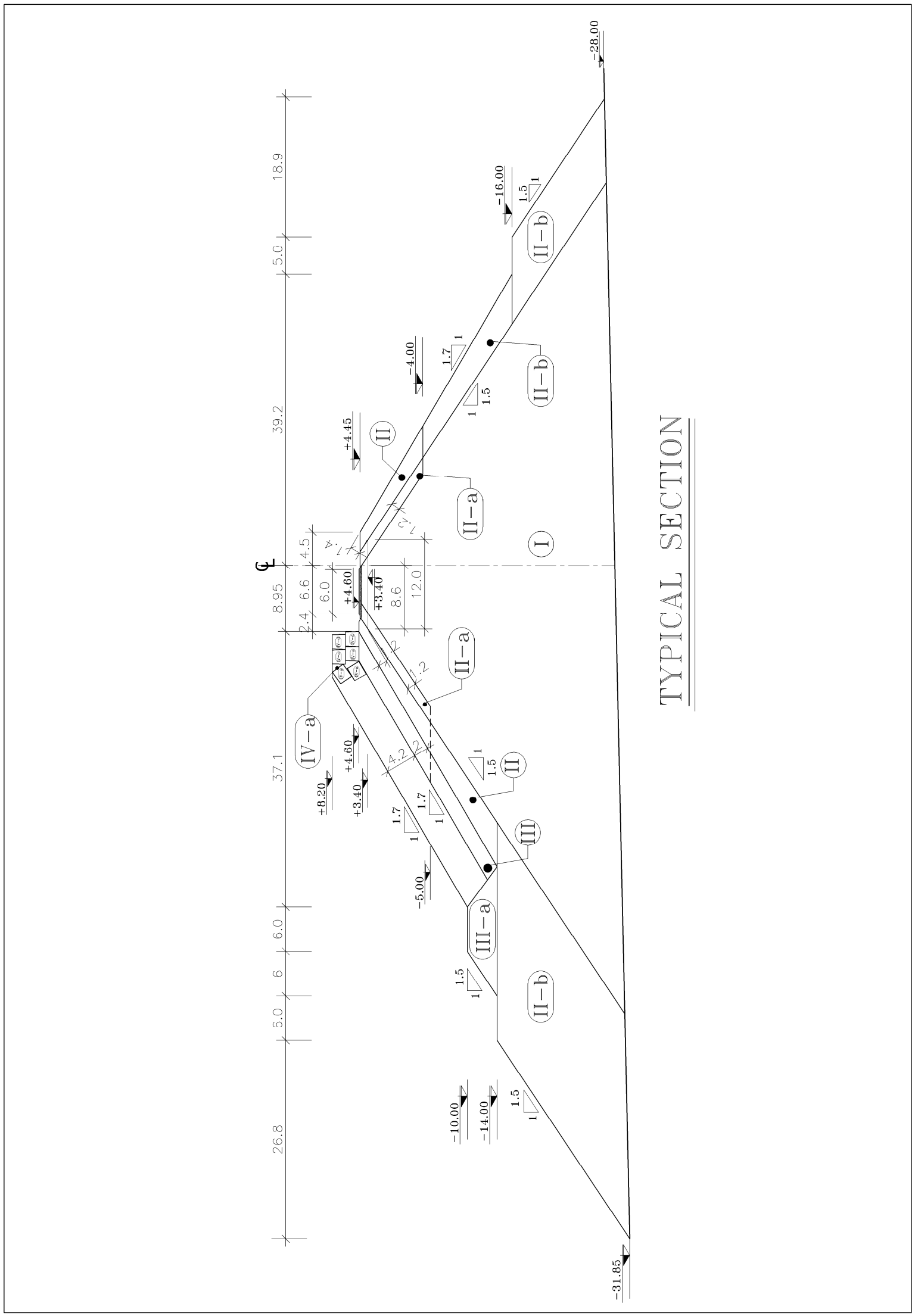

Figure 3. Typical Trunk Cross-Section Drawing of the Main Breakwater 


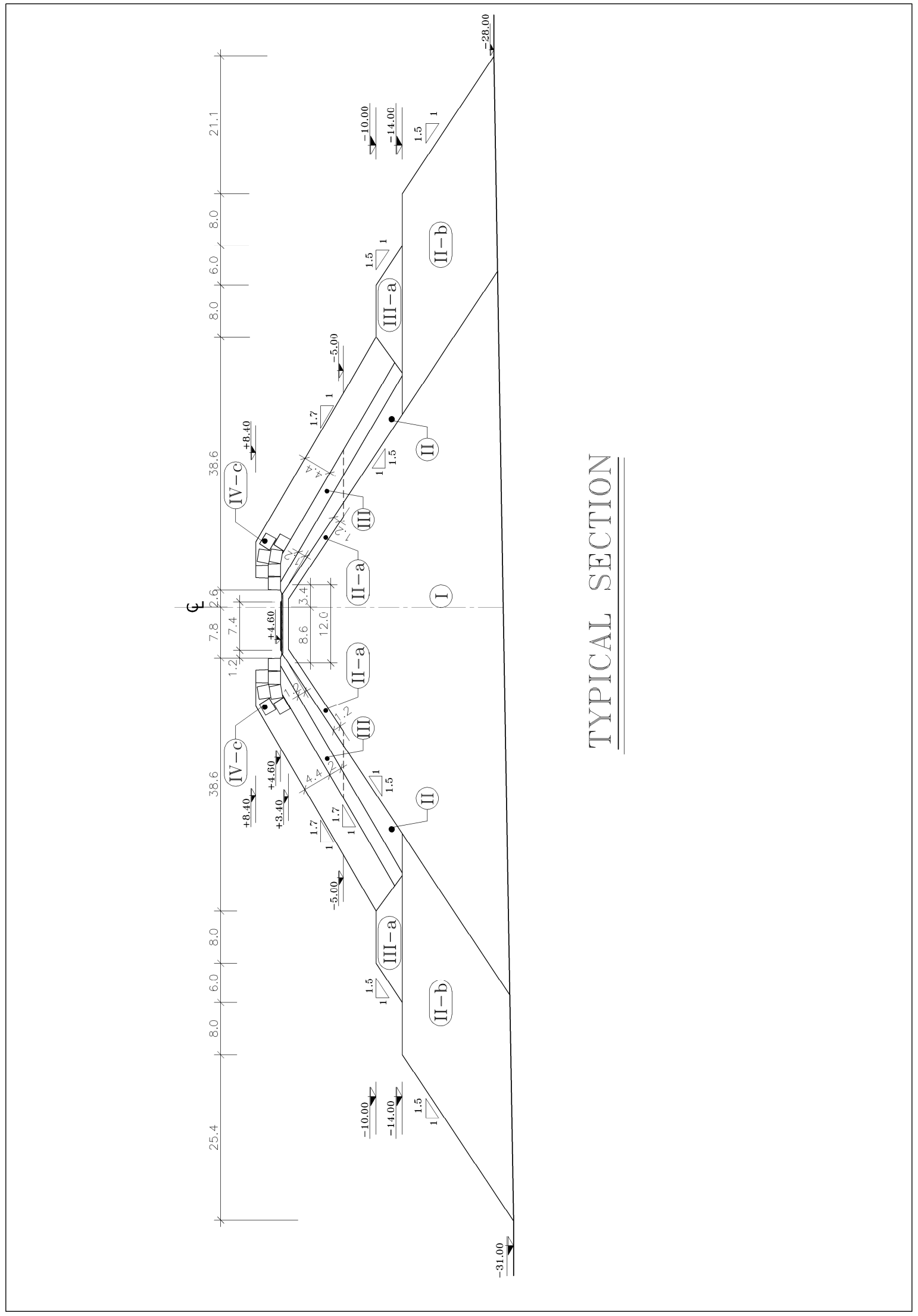

Figure 4. Typical Head Cross-Section Drawing of the Main Breakwater 


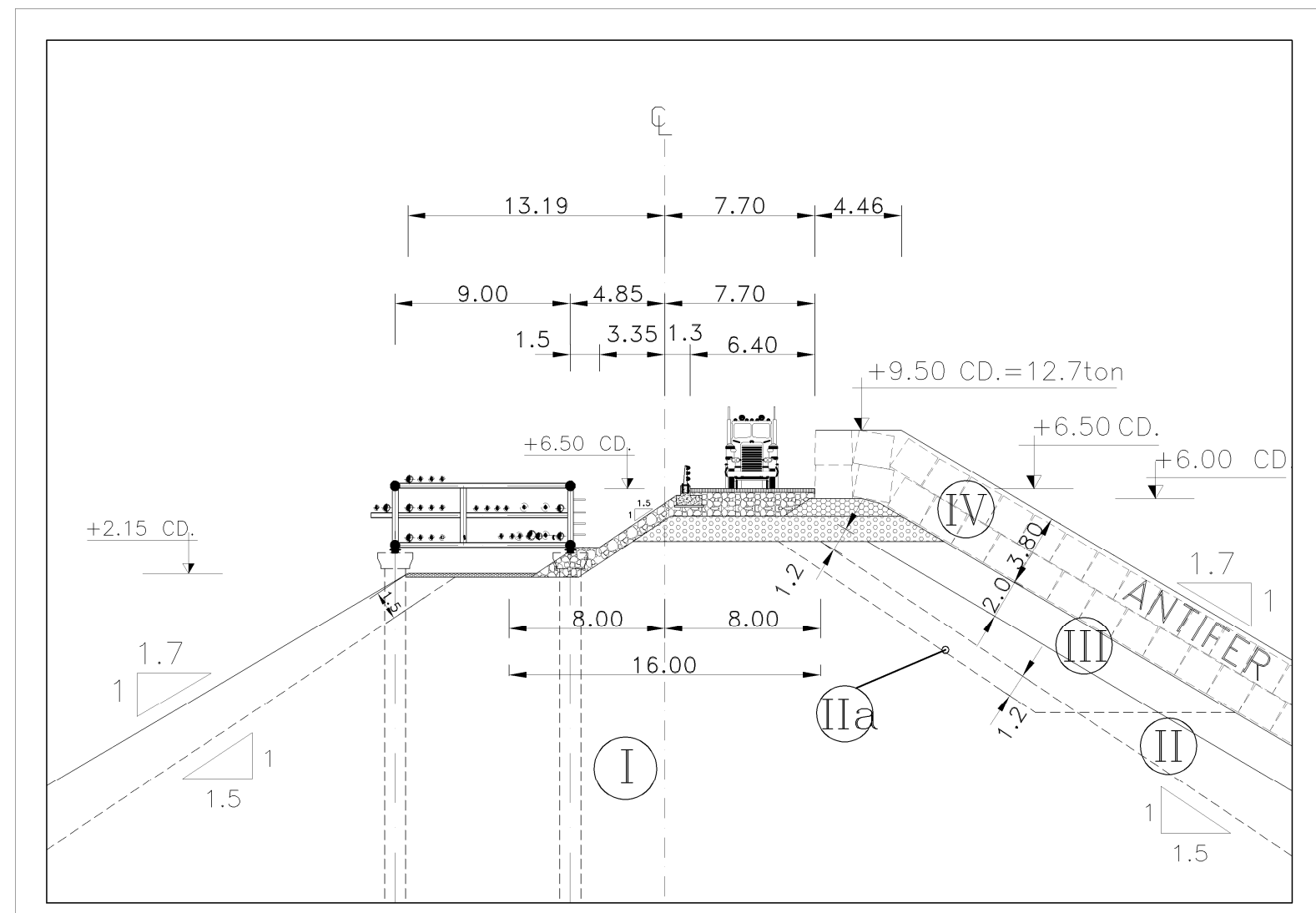

Figure 5. Typical Crest Cross-Section Drawing of the Main Breakwater

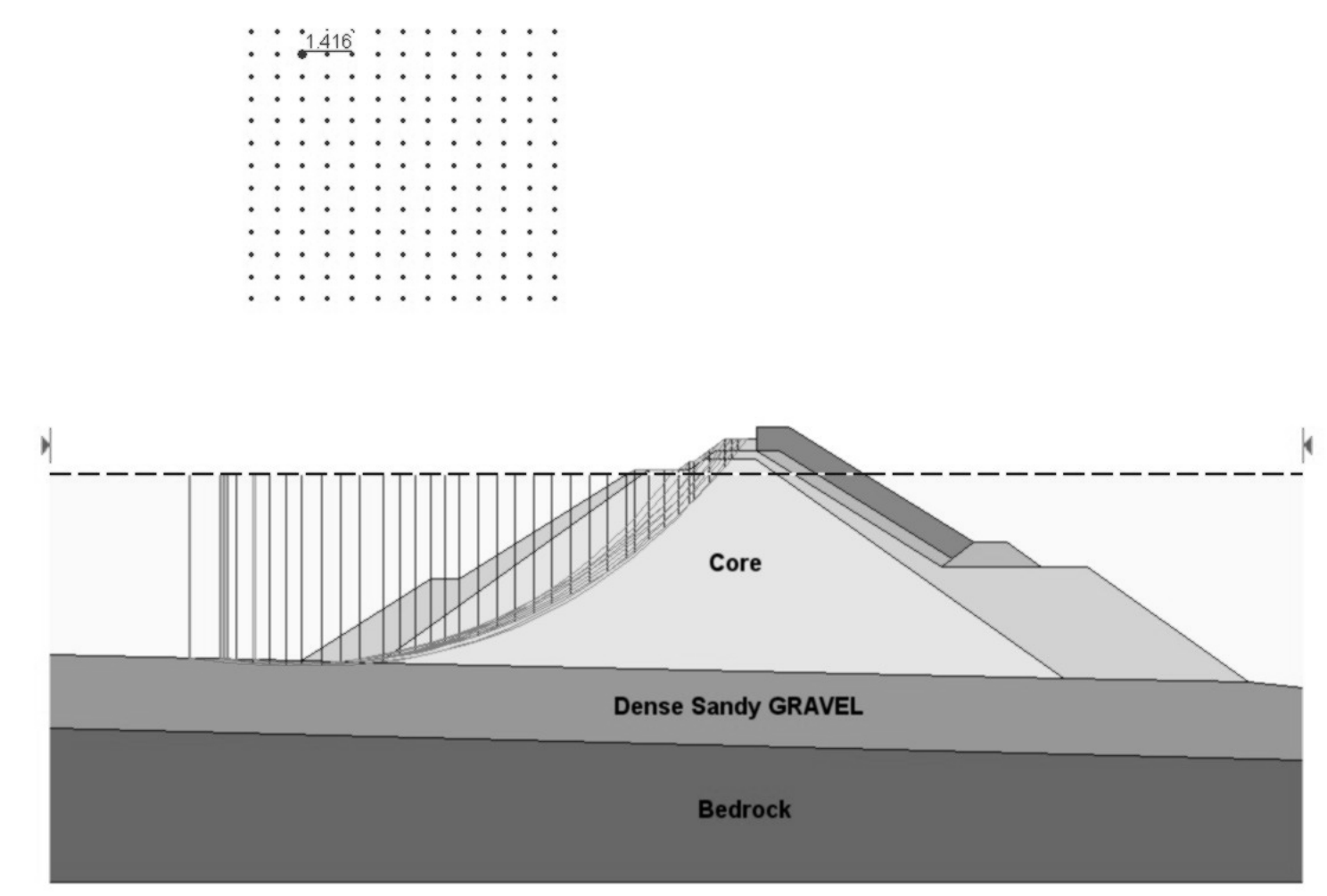

Figure 6. Limit Equilibrium Based Slope Stability of the Main Breakwater 


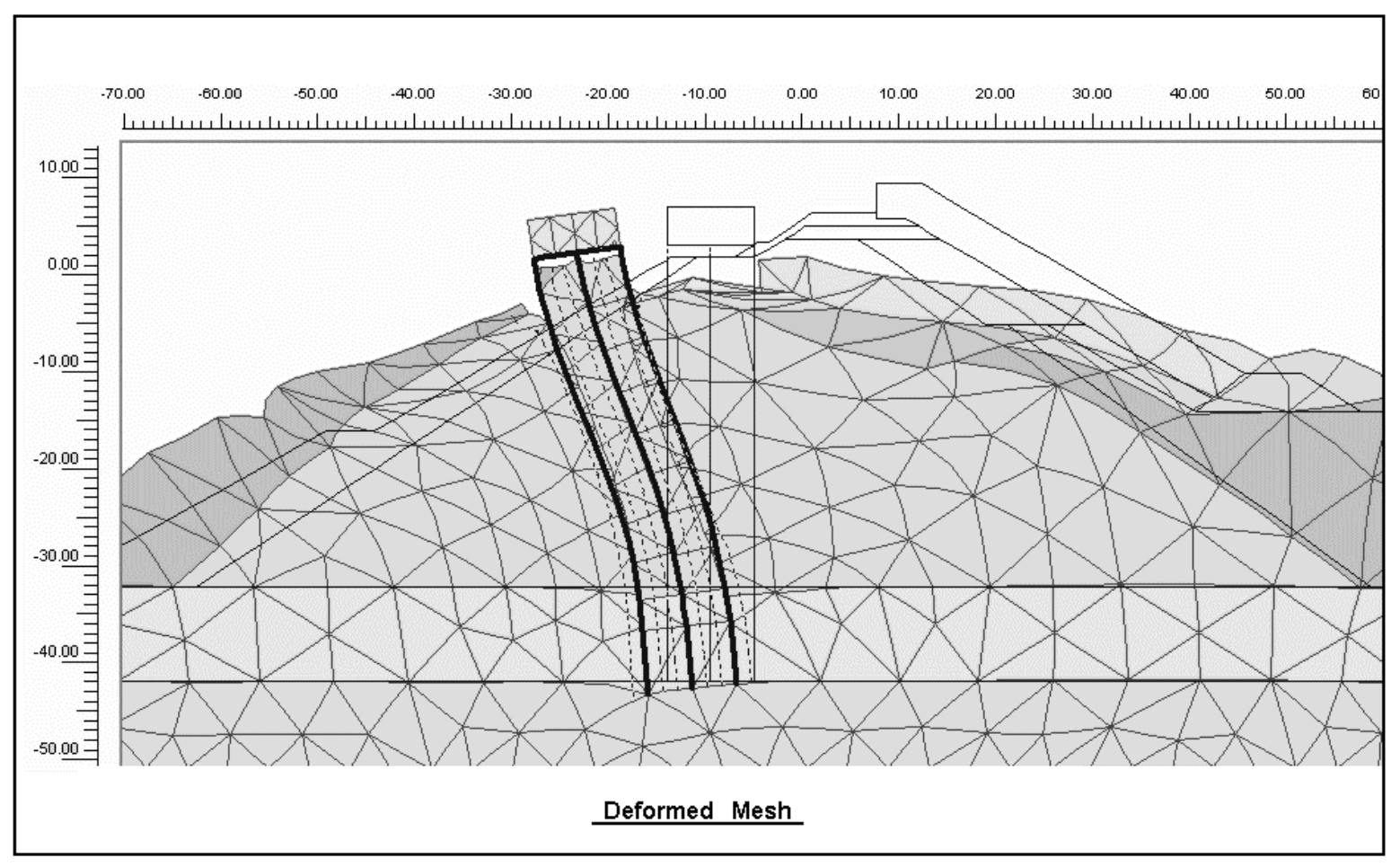

Figure 7. Breakwater and Pipe-Rack Substructure Deformations after the Design Earthquake

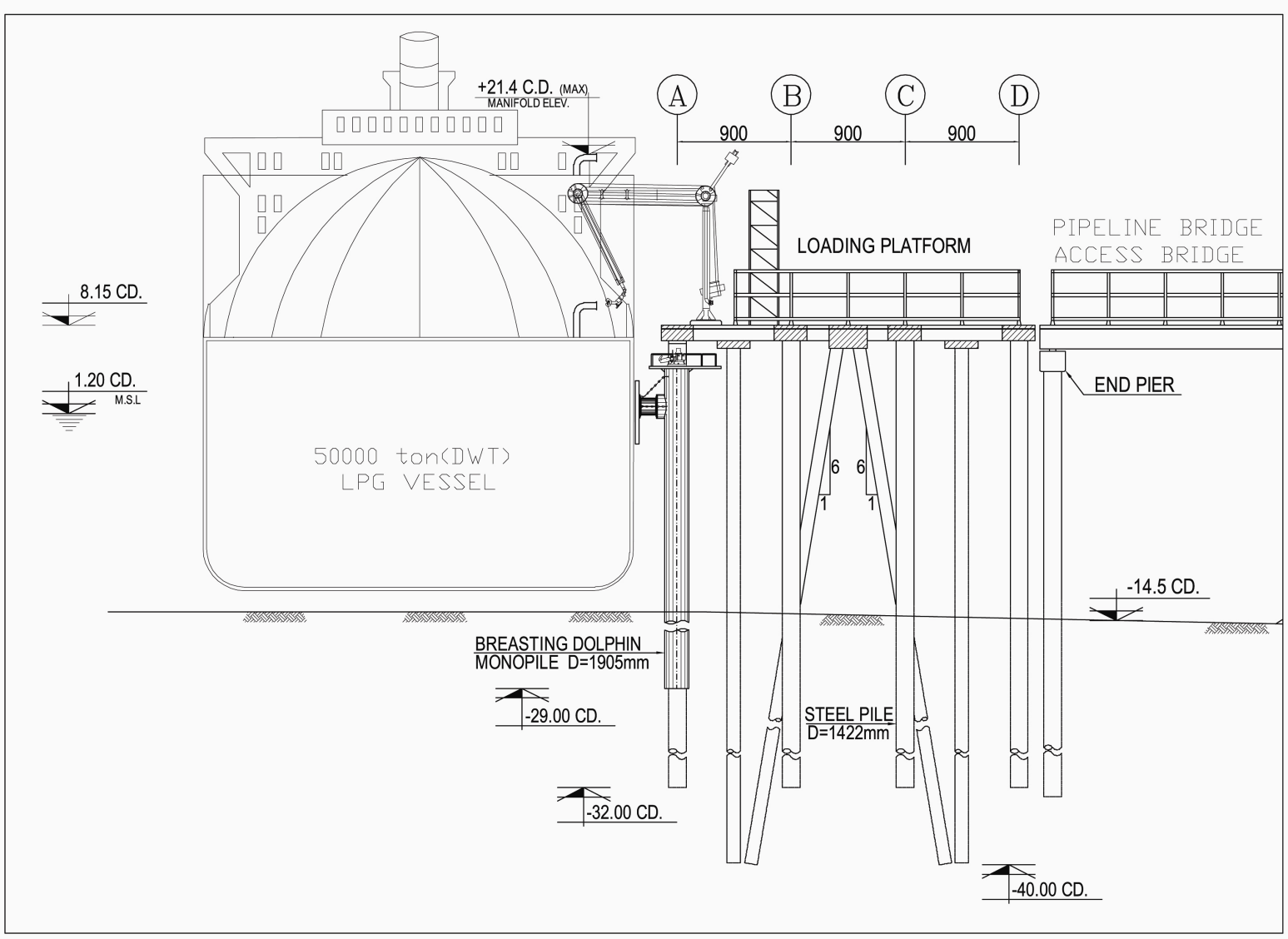

Figure 8. Typical Cross-Section Drawing of the Berths adjacent to the Lee Breakwater 


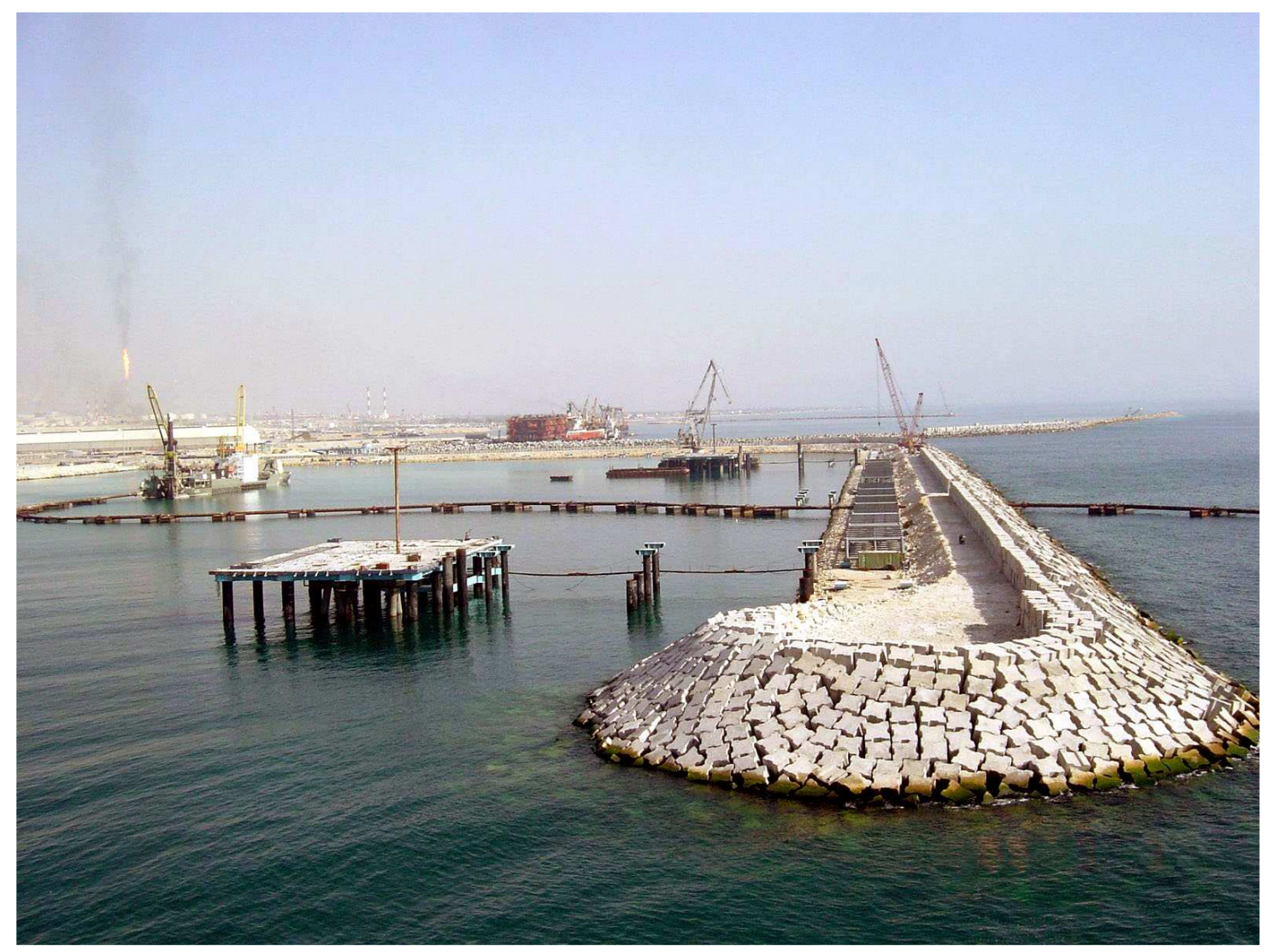

Figure 9. Head Section of the Lee Breakwater under construction.

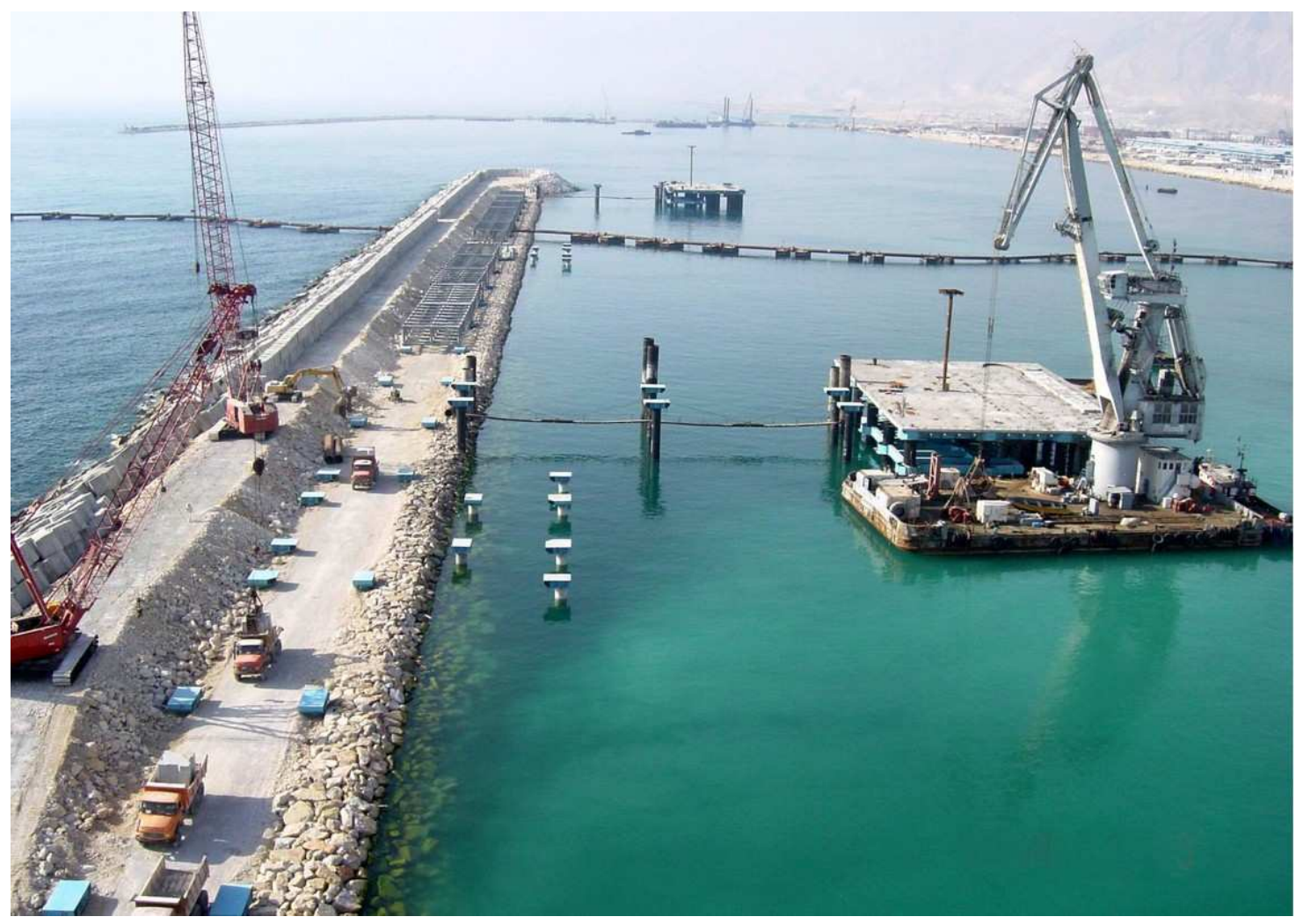

Figure 10. Piperack atop breakwater crest under construction. 